\title{
The religious lives of students at a South African university
}

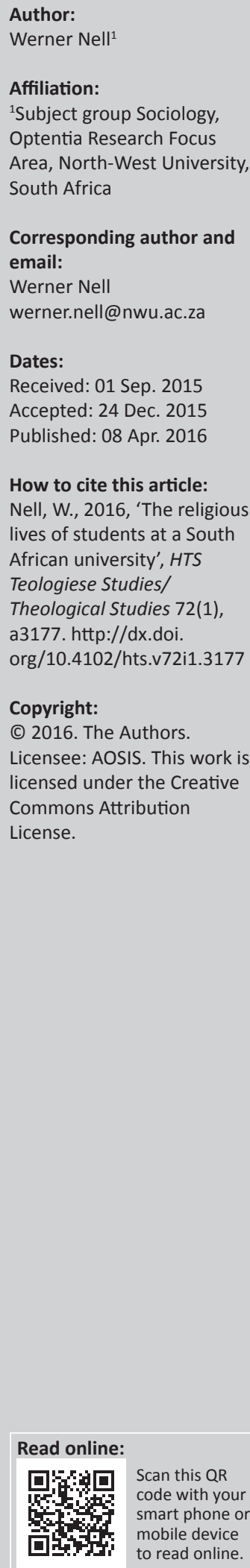

Whilst significant research has been conducted on religious affiliation and on general levels of religiosity in the South African context, few studies specifically investigated the religious lives of South African university students in a comprehensive way. This is unfortunate as such research could significantly inform and support the effectiveness of youth and student ministries. As such, this article explored the religious lives of students at a university in the Gauteng province of South Africa, focusing specifically on students' self-assessed religiosity, the maturity of their religious attitudes, their spiritual well-being, the religious practices in which they engage and the relationship between such practices and their spiritual well-being. Gender, racial and religious differences concerning these variables were also investigated. Data were collected from 356 undergraduate students by means of a structured survey consisting of the Spiritual Well-Being Questionnaire, the Religious Fundamentalism Scale and two other scales aimed at assessing religiosity and religious practices. Results indicated that 98.9\% of participants were religious with the majority (86.9\%) being Christian. Generally, students espoused highly fundamentalist religious attitudes but had high levels of spiritual well-being. Prayer and virtual or in-person attendance of religious gatherings such as church services were the most prevalent religious practices whereas fasting and meditation were practiced least. All practices were positively correlated with students' spiritual well-being. Based on these findings, the article concludes with several specific, practical recommendations relevant to student ministries and those working with university students in religious contexts.

\section{Introduction}

What do the religious lives of South African university students look like? Whilst several studies exist that report general levels of religiosity amongst the South African population (e.g. Diener, Tay \& Myers 2011; Lippman \& Keith 2006), very few studies specifically focus on university students. Furthermore, a thorough understanding of the religious lives of students (or any other group) involves far more than a mere assessment of their respective levels of religiosity. Integral to such an understanding, and highly relevant to the context of student ministries, is an assessment of students' religious maturity, spiritual well-being and the spiritual and religious practices in which they engage, as well as an understanding of how such practices are related to their spiritual well-being. These aims form the central focus of the present article, which approaches these topics from a predominantly psychological and sociological perspective.

\section{Religion in South Africa}

South Africa is generally regarded as a highly religious country in which between $85 \%$ (Diener et al. 2011) and $94.1 \%$ (Statistics South Africa 2013:32) of the population consider religion to play an important role in their daily lives. The vast majority $(85.6 \%)$ of South Africans are Christian (Statistics South Africa 2013:32). The term religiosity, as used in this article, is taken to refer to the degree to which individuals endorse a particular belief system, which involves specific practices, rituals or symbols that are associated with reverence for the transcendent or sacred. These may or may not include elements of spirituality, which is typically taken to refer to the degree to which persons seek and experience a personal sense of connection with the transcendent (Del Rio \& White 2012:123). However, understanding the religious lives of any given group of people involves far more than merely determining their religious affiliation and level of religiosity, as many studies aim to do (e.g. Diener et al. 2011; Lippman \& Keith 2006). Such an endeavour would need to include an assessment of a group's religious maturity or the extent to which their religious orientations and attitudes are characterised by fundamentalism. It should also include an assessment of the specific religious practices in which the group engages and the frequency with which they do so. Furthermore, the need exists to investigate whether and how these phenomena might vary according to gender, race and religious affiliation. 


\section{Fundamentalism and religious maturity}

An important dimension of religiosity is the relative level of religious fundamentalism (versus religious maturity) that characterises a given group. This concept is distinct from religiosity itself as it is possible to be highly religious and highly fundamentalist, and it is also possible to be highly religious and highly religiously mature, and vice versa (Ellison 1983:332). Religious fundamentalism is defined as follows (Altemeyer \& Hunsberger 1992):

\begin{abstract}
... the belief that there is one set of religious teachings that clearly contains the fundamental, basic, intrinsic, inerrant truth about humanity and deity; that this essential truth is fundamentally opposed by forces of evil which must be vigorously fought; that this truth must be followed today according to the fundamental, unchangeable practices of the past; and that those who believe and follow these fundamental teachings have a special relationship with the deity. (p. 118)
\end{abstract}

The relative level of fundamentalism that characterises a given group of people is important to evaluate as it has been found to be predictive of a variety of (mostly) problematic outcomes such as aggressive, hostile and prejudicial attitudes towards minority groups. Such individuals were also found to be far more likely to support the hunting down, arresting, torture and even execution of radical, criminal and homosexual people (Altemeyer \& Hunsberger 1992). Other researchers found that religious fundamentalism predicted increased levels of shame amongst Christians with low levels of spiritual maturity (Keller, Mollen \& Rosen 2015). Based on these and other findings, the degree of fundamentalism that characterises the religious orientation of a given group or individual is often seen as a significant indicator of the religious maturity of such an individual or group (Allport 1950; Fowler 1981; Streib, Wood \& Klein 2009; Wilber 2007). Whilst the interrelationships of these variables are complex and whilst the construct of religious maturity can certainly not be reduced to fundamentalism alone (Keller et al. 2015), this notion has been supported empirically by findings of very strong negative correlations between measures of religious maturity such as the Quest Scale and measures of religious fundamentalism (Altemeyer \& Hunsberger 1992), which '... gives some support to considering religious maturity and fundamentalism as being bipolar opposites' (James, Griffiths \& Pedersen 2011:215).

Relatively few studies have investigated fundamentalism amongst South African university students. In one such study, Pienaar, Beukes and Esterhuyse (2006) found that university students were characterised by high levels of religious fundamentalism and that such attitudes were associated with enhanced psychological well-being.

\section{Spiritual well-being}

When investigating religiosity and spirituality, it is not only the nature and extent of individuals' religiosity that matter but also their spiritual well-being. Gomez and Fisher (2003) propose a model in which spiritual well-being is conceptualised as consisting of four specific subdomains.
Spiritual health or well-being is regarded as a dynamic state of being that is affected by the degree to which people live in harmony within the context of relationships in these four domains of spiritual well-being. These include the personal domain, which involves the extent of harmony in the relationship with oneself; the communal domain, which involves relations with others; the environmental domain, which pertains to relations with nature and the transcendental domain, which involves the relationship with God or transcendental other. According to Gomez and Fisher (2003), a relationship of progressive and interrelated synergism exists between these domains as each domain builds on and in turn is built upon by other domains. However, these domains are also believed to cohere in a global dimension of spiritual well-being.

Research on spiritual well-being in a South African context is extremely limited. Amongst the very few studies that have been conducted, scores on all domains of spiritual well-being (with the exception of environmental spiritual well-being) have been found to be relatively high amongst South African adolescents. The scores were also found to be positively associated with higher levels of life meaning amongst members of this group (Burnell, Beukes \& Esterhuyse 2009).

\section{Religious practices}

An investigation of the religious lives of students, or any other group of people, requires inter alia an understanding of the religious practices in which they engage, the frequency with which they do so and the ways in which such practices are related to spiritual well-being. All religions are associated with a host of specific practices such as prayer, meditation, fasting, the attendance of religious services or gatherings, reading or studying religious scriptures, engaging in acts of service, et cetera (Wilber 2007). However, previous studies have found that the experience and practice of religiosity tend to be significantly influenced by culture (Utsey et al. 2005:251; Van der Merwe, Van Eeden \& Van Deventer 2010) and, to a lesser extent, by gender (Hekman 1993:144). As such, an investigation of religious practices and the unique ways in which such practices affect spiritual well-being within the context of specific populations such as university students needs to be conducted.

\section{The religious lives of South African university students}

It would appear that relatively little research has been conducted on the religious lives of South African students (Moodley, Esterhuyse \& Beukes 2012:123; Patel, Ramgoon \& Paruk 2009:267). In one of the few studies on this topic that could be found, Patel et al. (2009) investigated the differences in religiosity and religious well-being across religion, race and gender groups in a convenience sample of 235 South African university students. In this study, females reported higher levels of both religiosity and religious well-being than did males. White students were found to have lower levels of religiosity than black and Indian students. 
Furthermore, Muslim and Christian students had higher levels of religiosity than Hindu students, and Christian Indian students had higher scores on religious well-being that Hindu Indian students. Finally, they found that religious well-being was positively correlated with both religiosity and life satisfaction. In the 1999-2001 World Values Survey, $62.1 \%$ of South Africans between the ages of 18 and 24 indicated that they regarded religion as an important factor in their lives. Of those surveyed, $98.7 \%$ reported that they believed in God, and 69.3\% reported that God was very important in their lives (Lippman \& Keith 2006).

However, whilst religiosity is not infrequently measured as a demographic variable in social science studies, such assessments are usually restricted to an assessment of overall levels of religiosity and religious affiliation, and very limited information is typically gathered on the specific nature and extent of participants' religious lives. This gap is unfortunate as such knowledge could be useful to those working within the contexts of religious institutions and student ministries in attaining a better understanding of the religious profile of university students. The findings could also be of use to universities in sensitising them to the religious beliefs, practices and needs of their students, which might lead to the establishment of structures, groups or activities that more effectively address the religious aspects of students' lives. Such endeavours are likely to have significant positive consequences given the myriad of links between religiosity and various aspects of psycho-social well-being (Burnell et al. 2009; Nell 2014; Patel et al. 2009) and the fact that religiosity has been found significantly to affect university satisfaction amongst students (Bowman \& Smedley 2013) and is associated with a reduced likelihood of alcohol and drug abuse (Peltzer, Malaka \& Phaswana 2002). In light of these gaps, the main aim that was set for the present study was to investigate the religious lives of South African university students, which included an investigation of students' overall levels of religiosity, their religious affiliation, their spiritual well-being as well as the nature and frequency of the religious practices they engage in and the relationship such practices had with students' spiritual well-being. A final sub-aim of the study was to examine whether any significant gender, religious or racial differences existed in relation to these constructs.

\section{Research method and design}

The study was based on a quantitative cross-sectional survey design, which, in turn, is derived from a positivist ontology (Sarantakos 2013:31-33).

\section{Participants and procedure}

In total, 356 students, comprised of two separate groups, took part in the study. The first group consisted of 110 undergraduate social-science students in their final year of study. To obtain more diversity in the sample, the second group of participants $(n=246)$ consisted of first-year undergraduate students in social and economic sciences.
Participants in both groups completed the questionnaires voluntarily either at the end of an introductory lecture or during an unused time slot allocated to a tutorial lecture. Questionnaires were completed in a group setting in a penciland-paper format under the personal supervision of the researcher. All students were enrolled full-time at a university in the Gauteng province of South Africa. The average age of the participants was 21.38 years $(S D=4.74)$, with ages ranging from 18-53. However, $92.6 \%$ of participants were aged between 18 and 24 . As can be seen in Table 1, which provides an outline of the characteristics of the participant group, both genders and a wide variety of language or cultural and racial groups were represented in the sample. Overall, however, the sample was predominantly composed of black (especially Sesotho-speaking) and female participants.

\section{Data-collection measures}

Data for the study were collected by means of a structured questionnaire that was administered in a pencil-and-paper format. The first section of the questionnaire was aimed at gathering biographical information about the participants in terms of their age, gender, racial and language group as well as religious affiliation. To measure students' levels of overall religiosity, a single item was used which required students to self-assess how religious they considered themselves to be on a 5-point scale which ranged from 0 (not at all religious) to 4 (extremely religious). Previous research indicated that such a single-item measure is highly reliable in measuring religiosity amongst university students and that the results obtained from this item do not differ significantly from the findings obtained via multi-item measures of religiosity (Dollinger \& Malmquist 2009).

To measure spiritual well-being, I used the Spiritual WellBeing Questionnaire (SWBQ), which was initially developed by Gomez and Fisher (2003) and subsequently adjusted, standardised and validated on a sample of South African adolescents by Moodley et al. (2012). This scale was deemed to be a highly appropriate measure of spiritual well-being, given that it is based on a broader and more empirically based conceptualisation of spiritual well-being than other scales such as the Spiritual Well-Being Scale (SWBS) (Gomez \&

\begin{tabular}{llcc} 
TABLE 1: Characteristics of the participants $(n=356)$ & & \\
\hline Category & Variable & $f$ & $\%$ \\
\hline Gender & Male & 192 & 25.9 \\
\multirow{2}{*}{ Race } & Female & 263 & 74.1 \\
& Black & 328 & 92.4 \\
& White & 19 & 5.5 \\
& Mixed-race & 4 & 1.1 \\
Cultural group & Asian & 2 & 0.6 \\
& Sesotho & 145 & 41 \\
& isiZulu & 68 & 19.2 \\
& Setswana & 43 & 12.1 \\
& isiXhosa & 31 & 8.8 \\
& Afrikaans & 15 & 4.2 \\
& English & 15 & 4.2 \\
& Northern Sotho & 20 & 5.6 \\
\hline & Other & 17 & 4.7 \\
\hline
\end{tabular}


Fisher 2003). Furthermore, (to my knowledge) it is the only such scale that has been standardised on and specifically adapted to a South African student population. Additionally, using the scale as adapted by Moodley et al. would render the findings of the present study comparable to those reported by them, thereby building on the initial findings. This scale consists of 20 items, which in turn comprise 4 sub-scales of 5 items each, measuring the four domains of spiritual wellbeing as proposed by Gomez and Fisher (2003). These domains include personal, communal, environmental and transcendental domains. In turn, these four first-order latent variables load onto a single second-order latent variable spiritual well-being. A series of four studies was conducted by Gomez and Fisher (2003), and results of both exploratory and confirmatory factor analyses confirmed the construct validity and factorial independence of the four domains of spiritual well-being as measured by the SWBQ. Furthermore, results show that this scale represents a reliable measure of spiritual well-being and that the scale has adequate convergent, discriminant and incremental validity. The scale, as adjusted by Moodley et al. (2012), exhibits acceptable internal consistency coefficients in relation to each of the four sub-scales as well as the global score of the SWBQ. Factor analysis confirms the existence of a four-factor structure with all items loading onto their respective factors and the four latent variables in turn loading onto a single second-order factor as hypothesised (Moodley et al. 2012).

This study also aimed to investigate the degree of religious maturity and fundamentalism amongst the student group, and to do so, the revised 12-item Religious Fundamentalism Scale (RFS) (Altemeyer \& Hunsberger 1992) was used. Though initially comprised of 20 items, Altemeyer and Hunsberger subsequently created a revised and psychometrically improved and robust 12-item version of the scale, which has been shown to be a highly valid and uni-dimensional measure of religious fundamentalism (Altemeyer \& Hunsberger 2004). The scale has 12 items which are rated on a 9-point scale, ranging from 'very strongly disagree' (-4) to 'very strongly agree' (+4). Initial validation studies indicate that the RFS exhibits a single-factor structure, which explained $53.5 \%$ of the variance in the items. Furthermore, the scale had good psychometric reliability and validity when administered to USA college students and their parents. Finally, the convergent validity of the RFS with other scales measuring similar or related constructs was found to be acceptably high (Altemeyer \& Hunsberger 2004). The reliability of the items in the scale was high with alpha coefficients of 0.92 to 0.93 being reported. This scale was selected due to these robust psychometric properties as well as the fact that it is a widely used measure of religious fundamentalism which has been shown to be psychometrically reliable cross-culturally and across different religious denominations (Baum 2009). Furthermore, the scale was found to have very high levels of reliability (Cronbach's alpha $=0.91$ ) when administered to a sample of Christian participants (which is the religious affiliation of the vast majority of participants in the present study) (Keller et al. 2015).
To investigate the type of religious practices in which students engage as well as the frequency with which they do so, a questionnaire was developed which listed a variety of religious practices and requested students to rate the frequency with which they engaged in each of these practices, if at all. These practices included praying, meditating, reading religious scriptures or books, talking about religion with others (excluding religious services), reflecting on life events in terms of religious beliefs, praying before meals, deliberately working on changing or aligning behaviour with religious values and beliefs, rendering service to others that is religiously inspired or motivated, using social media such as Twitter, Facebook, et cetera to practice or share their religiosity and providing religious teaching, guidance or counselling to others. These items were measured on a 6-point scale ranging from 'never' to 'more than once a day'. However, given the nature of these activities, the remaining practices of attending religious services and gatherings, listening to religious services on the radio or television, taking part in religious or rituals and fasting were measured on a 6-point scale ranging from 'never' to 'more than once a week'.

\section{Data analysis}

Data from the questionnaires were captured by the statistical consultation service department of the North-West University. The initial screening and analysis of the data were done in SPSS 21.0 and involved examining the data set for outliers and errors. Following this, the reliability and validity of the RFS and SWBQ was investigated by means of CFA in Mplus version 7.0 (Muthén \& Muthén 2012). This process involved the specification of a structural model for each scale in which items pertaining to each scale and/or sub-scale were specified as loading onto the latent construct that they purport to measure. These models were then assessed in Mplus in terms of the extent to which they fit the actual data, using the Chisquare statistic, the Standardised Root Mean Residual (SRMR) and the Root Means Square Error of Approximation (RMSEA) as absolute fit indices. I also used the Tucker-Lewis Index (TLI) and the Comparative Fit Index (CFI) as incremental fit indices (Wang \& Wang 2012:19). As recommended by Wang and Wang (2012:19), the threshold for acceptable model fit on the CFI and TLI was set to the 0.90 level whereas values of 0.06 or less were deemed as indicating acceptable fit in relation to the RMSEA and SRMR. To compare competing models, the Akaike Information Criterion (AIC) and Bayes Information Criterion (BIC) were used with lower AIC and BIC scores taken to represent improved fit (Wang \& Wang 2012:22).

Once the psychometric reliability of the above scales was established, descriptive statistics such as means and standard deviations were obtained in SPSS. Additionally, Pearson's product moment correlation coefficients were computed between variables in order to identify their inter-relationships. To assess between-group differences concerning various aspects of religiosity, independent $t$-tests and multiple analysis of variance (MANOVA) were used. MANOVAs are used to assess differences between groups when more than one 
dependent variable is involved as is the case with the four sub-scales of the SWBQ (Brace, Kemp \& Snelgar 2012:309). Independent $t$-tests were used to assess the statistical significance of mean differences between groups in cases where comparisons were restricted to two groups. In cases where the assumption of the homogeneity of variance was met, Cohen's $d$ was used to determine the size of these differences with effect sizes of 0.2 being regarded as small, 0.5 as medium and 0.8 as large (Brace et al. 2012:11). In the case of religious affiliation, comparisons were restricted to Christian students and those affiliating themselves with traditional African religious beliefs, given the small number of participants in certain categories. Similarly, concerning race, comparisons were restricted to black and white students. In all cases, the cut-off level for statistical significance was set at $p<0.05$.

\section{Ethical considerations}

The study was approved by the ethics committee of the Vaal Triangle Campus of the North-West University. All potential participants were informed of the nature and scope of the study as well as of what their involvement would entail in terms of possible risks (which were minimal) and the time required to complete the questionnaires. Participants were also assured that they would have the right to refuse participation or to withdraw their participation at any stage of the process without penalty and that their responses would be treated confidentially if they did choose to participate. Informed and signed consent was obtained from every participant, and questionnaires were administered in ways that did not interfere with students' instruction time. To protect the confidentiality of participants' responses, data was captured without any identifying particulars, and the data set was password protected.

\section{Reliability and validity}

The reliability and validity of the results were supported by the use of scales that have been proven to be psychometrically robust and by conducting both reliability and validity analyses (by means of Cronbach alpha coefficients and CFA) of the SWBQ and the RFS. Additionally, data collection was personally supervised by the researcher, and data capturing was conducted by an experienced statistician.

\section{Results}

As an initial step in the data-analysis process, confirmatory factor analysis (CFA) of the items in the Spiritual Well-Being Questionnaire was conducted in Mplus 7.1 to investigate whether the factor structure reported by Moodley et al. (2012) would be replicated in the present study. To do so, a measurement model consisting of four latent factors corresponding to the sub-scales of the SWBQ was specified in Mplus 7.1. A second-order latent factor representing the total SWBQ score was also specified with the four first-order latent variables specified as loading onto this factor. The model was found to fit the data on all indices except the TLI $\left(\chi^{2}=390.03\right.$, $d f=166, \mathrm{TLI}=0.89, \mathrm{CFI}=0.91, \mathrm{RMSEA}=0.06, \mathrm{SRMR}=0.06$,
$\mathrm{AIC}=15,408.77, \mathrm{BIC}=15,656.41)$. A large modification index (49.48) occurred between item 4 (I feel a connection between myself and nature) and item 10 (I feel one with nature) of the environmental sub-scale. Given that these items are highly similar, it was deemed theoretically justifiable to re-specify a model in which the error variances of these items were allowed to co-vary. This resulted in a model with significantly improved fit as can be seen from the fact that this model exhibits much smaller AIC and BIC values and a TLI score that indicates good fit $\left(\chi^{2}=343.14, d f=165\right.$, TLI $=0.92$, $\mathrm{CFI}=0.93, \mathrm{RMSEA}=0.06, \mathrm{SRMR}=0.06, \mathrm{AIC}=15,347.98$, $\mathrm{BIC}=15,599.48)$. All items loaded acceptably well onto their respective latent factors (all $>0.51$ ). The model accounted for $26.1 \%$ of the variance in the transcendental sub-scale, $40.7 \%$ of the variance in the environmental sub-scale and $88.8 \%$ and $80.5 \%$ of the variance in the communal and personal subscales, respectively. As such, the findings derived from this scale are likely to be reliable and valid.

As with the SWBQ, the RFS was also subjected to CFA in Mplus in the current study. Results indicated that the reversephrased items loaded differently than the directly phrased ones. As such, it was decided to retain only the directly worded items, which measure fundamentalist attitudes in a more explicit manner. The re-specified model exhibited acceptable fit $\left(\chi^{2}=373.69, d f=165, \mathrm{TLI}=0.92, \mathrm{CFI}=0.93\right.$, RMSEA $=0.05$, SRMR $=0.05)$, suggesting that the scale measured the construct of fundamentalism in a reliable way.

Table 2 provides an overview of the means, standard deviations, Cronbach alpha coefficients and inter-variable correlations for all scales and sub-scales for the entire participant group. Table 3 contains mean scores and standard deviations for all items and scales according to gender, race and religion.

As revealed in Table 2, the Cronbach alpha reliability coefficients of all scales and sub-scales used in this study were above the threshold for acceptable reliability of 0.7 that is typically proposed for the social sciences (Brace et al. 2012:382). As such, the scales are likely to have measured their underlying latent constructs in a reliable manner.

The first part of the questionnaire assessed students' religious affiliation as well as their self-assessed level of religiosity. Concerning the former, results revealed that, amongst the $98.9 \%$ of participants who considered themselves to be religious (or spiritual) to one degree or another, the vast majority of participants (86.9\%) were Christian whereas $5.4 \%$ of participants belonged to traditional African religions, 3.4\% considered themselves spiritual but not religious, $1.4 \%$ were Muslim, $0.3 \%$ Buddhist, and $2.6 \%$ belonged to 'other' religious groupings. These findings closely echo those reported in the 2013 General Household Survey where $85.6 \%$ of the South African population were found to be Christian, 2\% Muslim, $5.6 \%$ atheists, and 5\% belonged to traditional African religions (Statistics South Africa 2013:33). 
TABLE 2: Means, standard deviations, Cronbach alpha coefficients and correlations for religiosity, spiritual well-being and fundamentalism for the total research group.

\begin{tabular}{|c|c|c|c|c|c|c|c|c|c|c|}
\hline Scale & $N$ & $M$ & $S D$ & $\alpha$ & Relig & SWB-Tra & SWB-Env & SWB-Com & SWB-Per & SWB-tot \\
\hline Religiosity & 353 & 2.63 & 0.83 & - & - & - & - & - & - & - \\
\hline SWB-Tra & 333 & 21.5 & 3.82 & 0.89 & $0.51 * *$ & - & - & - & - & - \\
\hline SWB-Com & 341 & 19.01 & 3.05 & 0.78 & $0.21 * *$ & $0.38 * *$ & $0.51 * *$ & - & - & - \\
\hline SWB-Per & 343 & 20.5 & 3.23 & 0.8 & $0.27 * *$ & $0.47 * *$ & $0.44 * *$ & $0.65 * *$ & - & - \\
\hline Fundamentalism & 315 & 1.71 & 1.48 & 0.75 & $0.49 * *$ & $0.65 * *$ & 0.04 & $0.21 * *$ & $0.23 * *$ & $0.37 * *$ \\
\hline
\end{tabular}

$M$, mean; $S D$, standard deviation.

SWB-Tra = transcendent spiritual well-being; SWB-Env = environmental spiritual well-being; SWB-Com = communal spiritual well-being; SWB-Per = personal spiritual well-being; SWB-Tot = total spiritual well-being.

Religiosity was measured on a 0 to 4 -point scale.

Mean scores for all subscales of the SWBQ range from 5 to 25 .

Fundamentalism was measured on a scale ranging from -4 to +4 .

$*, p<0.05 ; * *, p<0.01$

TABLE 3: Mean scores and standard deviations for all scales according to gender, race and religion.

\begin{tabular}{|c|c|c|c|c|c|c|c|c|c|c|c|c|}
\hline \multirow[t]{3}{*}{ Scale } & \multicolumn{4}{|c|}{ Gender } & \multicolumn{4}{|c|}{ Race } & \multicolumn{4}{|c|}{ Religion } \\
\hline & \multicolumn{2}{|c|}{ Male } & \multicolumn{2}{|c|}{ Female } & \multicolumn{2}{|c|}{ Black } & \multicolumn{2}{|c|}{ White } & \multicolumn{2}{|c|}{ Christian } & \multicolumn{2}{|c|}{ African religious beliefs } \\
\hline & $M$ & $S D$ & $M$ & $S D$ & $M$ & $S D$ & $M$ & $S D$ & $M$ & $S D$ & $M$ & $S D$ \\
\hline Religiosity & 2.52 & 0.93 & 2.67 & 0.79 & 2.64 & 0.83 & 2.47 & 0.91 & 2.7 & 0.79 & 2.21 & 0.71 \\
\hline SWB-Tra & 20.83 & 4.19 & 21.75 & 3.67 & 21.61 & 3.68 & 19 & 5.58 & 21.96 & 3.23 & 18.58 & 4.62 \\
\hline SWB-Env & 18.01 & 4.11 & 16.71 & 3.94 & 17.04 & 4.02 & 18.39 & 4.05 & 17.07 & 4 & 16.39 & 3.15 \\
\hline SWB-Com & 18.82 & 3.25 & 19.08 & 2.98 & 19.06 & 3.09 & 18 & 2.29 & 19.07 & 2.98 & 18.82 & 3.15 \\
\hline SWB-Per & 20.65 & 3.07 & 20.43 & 3.3 & 20.54 & 3.27 & 19.53 & 2.89 & 20.63 & 3.15 & 20.17 & 3.7 \\
\hline SWB-Tot & 19.54 & 2.76 & 19.52 & 2.67 & 19.57 & 2.72 & 18.77 & 2.42 & 19.66 & 2.61 & 18.92 & 2.49 \\
\hline Fundamentalism & 1.25 & 1.68 & 1.88 & 1.38 & 1.78 & 1.4 & 0.5 & 2.33 & 1.92 & 1.28 & 0.82 & 1.75 \\
\hline
\end{tabular}

$M$, mean; $S D$, standard deviation.

SWB-Tra = transcendent spiritual well-being; SWB-Env = environmental spiritual well-being; SWB-Com = communal spiritual well-being; SWB-Per = personal spiritual well-being; SWB-Tot = total spiritual well-being.

Religiosity was measured on a 0 to 4 -point scale.

Mean scores for all subscales of the SWBQ range from 5 to 25 .

Fundamentalism was measured on a scale ranging from -4 to +4 .

Overall, the participants considered themselves to be quite religious. Expressed in terms of frequencies, $1.1 \%$ of participants considered themselves to be non-religious, $5.7 \%$ viewed themselves as mildly religious, $37.5 \%$ as moderately religious, $43.6 \%$ as very religious, and $13.6 \%$ of the participants regarded themselves as being extremely religious. As such, $98.9 \%$ of students in the sample were religious to one degree or another. Whereas no statistically significant differences in religiosity were found between either male and female or white and black participants, an independent $t$-test confirmed that Christian respondents considered themselves to be more religious than those espousing traditional African religious beliefs ( $t=2.63, d f=321, p=0.01$, two-tailed, mean difference $=0.49,95 \%$ CI: 0.12 to 0.85$)$. This represents a fairly large difference (Cohen's $d=0.65)$. However, in their study, Patel et al. (2009) found that female and black South African university students were more religious than male and white students, respectively. The reasons for these divergent findings remain unclear at present, and additional research is required to identify factors that might account for gender and racial differences in religiosity.

The Revised Fundamentalism Scale was used to assess the religious maturity of the participants. As shown in Table 2, the student group was characterised by high levels of religious fundamentalism, indicating that they are likely generally inclined towards religious views that are somewhat conservative, rigid, dogmatic and lacking in terms of interreligious tolerance. Female students tended to hold more fundamentalist views than males as confirmed by an independent $t$-test $(t=3.06, d f=119.56, p=0.003$, two-tailed, equality of variances not assumed; mean difference $=0.63$, 95\% CI: -1.04 to -0.22 ). Furthermore, Christian students were found to espouse more fundamentalist views than those who associate themselves with traditional African religious beliefs $(t=3.26, d f=285, p=0.01$, two-tailed, mean difference $=1.09,95 \%$ CI: 0.43 to 1.75$)$, representing a fairly large difference (Cohen's $d=0.72$ ). Finally, black students scored substantially higher on fundamentalism than white students $(t=2.36, d f=18.87, p=0.03$, two-tailed, equality of variances not assumed; mean difference $=1.28$, 95\% CI: 0.14 to 2.41 ).

As further part of the study, students' levels of spiritual wellbeing were measured with the SWBQ. This scale measures four dimensions of spiritual well-being, which include transcendent, environmental, communal and personal spiritual well-being. Results (Table 2) indicate that the student group is characterised by high levels of transcendental well-being $($ mean $=21.5 ; S D=3.82)$, and as such, they experience a strong and significant connection to a higher power that contributes to their spiritual well-being. The scores of the student group on this scale were significantly higher than the norms indicated by Gomez and Fisher 
(2003:1983) of $13.00(S D=6.06)$ and marginally higher than the score of $20.26(S D=4.24)$ obtained by Burnell et al. (2009:14) in a sample of 689 South African adolescents aged between 16 and 20 years. Likewise, students also had high levels of personal spiritual well-being (Mean $=20.5 ; S D=3.23$ ), suggesting that their spirituality is associated with elevated levels of inner harmony, joy, peace and self-understanding. Again, the score obtained in the present study was slightly higher than those reported by Gomez and Fisher (2003:1983) (mean $=19.97, S D=3.39)$ and Burnell et al. (2009: 14) (mean = 19.68; $S D=3.34$ ). Communal well-being was above average (mean $=19.01 ; S D=3.05)$ but lower than transcendent and personal well-being. Burnell et al. (2009: 14) found similar levels of communal well-being in their study (mean $=19.17$, $S D=3.05)$ whereas Gomez and Fisher (2003:1983) reported a slightly higher norm of $20.77(S D=3.16)$ for this sub-scale. The dimension which received the lowest score was environmental well-being $($ mean $=17.06 ; S D=4.01)$, indicating that this aspect of spirituality might be relatively lacking and/or neglected within the context of the student group. However, the students' scores on environmental spiritual well-being were marginally higher than those found by Burnell et al. (2009:14) (mean = 16.83; $S D=3.78)$ and Gomez and Fisher (2003:1983) (mean $=16.69 ; S D=4.23)$.

A one-way, between-subjects, multivariate analysis of variance (MANOVA) was conducted in order to assess the relationship between gender (as between-subjects factor) and the four dimensions of spiritual well-being (which constituted the dependent variables). Box's test was non-significant, confirming that data did not violate the assumptions of homogeneity of variance-covariance matrices. Levene's $p$ was larger than 0.05 for both genders, indicating that there is equality of error variance between the two groups. Finally, moderate correlations exist between the dependent variables, all indicating that the results of a MANOVA test are likely to be reliable (Brace et al. 2012:312). A statistically significant difference between the two groups was found on the combined dependent variable, spiritual well-being $(\mathrm{F}(4,301)=5.44, p<0.000 ;$ Wilks's Lambda $=0.93$; partial $\left.\eta^{2}=0.07\right)$. To guard against a type 1 error, dependent variables were analysed using a Bonferroni-adjusted alpha level of 0.013. Results indicated that the only statistically significant difference between the two genders occurred on the environmental well-being sub-scale of the SWBQ $\left(\mathrm{F}(1,304)=6.51, p=0.011\right.$, partial $\left.\eta^{2}=0.02\right)$. More specifically, the mean score obtained by males $(M=18.02)$ was higher than that obtained by females $(M=16.72)$. Given the unequal and small sample sizes of non-Christian and white participants, MANOVA could not be employed to investigate differences between religious and racial groups (Brace et al. 2012:312), and mean differences between these groups were investigated by means of independent $t$-tests instead. No statistically significant racial differences were found concerning any dimension of spiritual well-being. However, Christian students had significantly higher levels of transcendent well-being than students espousing traditional African beliefs $(t=3.14, d f=19.20, p=0.005$, two-tailed, equality of variances not assumed; mean difference $=0.68$, 95\% CI: 0.22 to 1.13 ).

Pearson's product-moment correlations were used to examine the interrelationships between students' levels of religiosity, fundamentalism and spiritual well-being. As is revealed in Table 2, students' overall level of religiosity exhibited significant positive correlations with all other variables. In particular, very strong relationships were noted between religiosity, transcendental spiritual well-being and fundamentalism, suggesting that those who are more religious are more likely to experience transcendental spiritual well-being and to espouse more fundamentalist religious attitudes than those who are not. Students' scores on the four sub-scales of the SWBS correlated positively with each other, thereby confirming that these factors are interrelated. With the exception of environmental spiritual well-being, which was unrelated to fundamentalism, all the sub-scales of the SWBS were positively correlated with fundamentalism, suggesting that holding fundamentalist attitudes might actually enhance (or merely be associated with) personal, transcendent and communal spiritual wellbeing amongst the participant group.

In order to obtain a more comprehensive understanding of the religious lives of students, all participants in the study were also asked about the frequency with which they engaged in specific religious practices. The results of this inquiry are presented in Table 4 .

As is clear from Table 4, the religious practice in which students engaged most frequently was prayer, both generally and specifically before mealtimes. Attendance of Church and/or other religious services also counted amongst the most highly practiced religious activities, suggesting that students are still actively and regularly attending religious gatherings such as church services. In similar vein, a very large number of students reported that they listen to religious services on the radio or the television, which indicates that virtual and/or in-person attendance of religious services constitutes the second most significant religious practice amongst the student group. Other spiritual practices in which students engaged fairly frequently included actively working on changing their own behaviour to align it with their religious values, talking to others about religious matters, sometimes by means of social media such as Facebook, and engaging in acts of religiously motivated service to others. The practices in which students engaged the least were meditation and fasting, suggesting that these practices do not play a significant role in the religious lives of the student group. A few notable gender-based differences emerged concerning the frequency with which students engaged in religious practices. The largest of these was that males reported attending religious services or gatherings significantly more often than females $(t=-3.29, d f=128.41$, $p=0.001$, two-tailed, equality of variances not assumed; mean difference $=0.77,95 \%$ CI: -1.23 to -0.31 ). Moreover, males were more likely than females to read religious or 
TABLE 4: Descriptive statistics in relation to frequency with which students engaged in specific religious practices, and correlations with overall spiritual well-being.

\begin{tabular}{|c|c|c|c|c|}
\hline Religious practice & $N$ & $M$ & $S D$ & Correlation with SWB \\
\hline Praying & 354 & 4.93 & 1.25 & $0.34 * *$ \\
\hline Attending religious services & 352 & 4.77 & 1.46 & $0.26 * *$ \\
\hline Saying grace before meals & 352 & 4.61 & 1.65 & $0.32 * *$ \\
\hline Listening to religious services on TV or radio & 354 & 4.56 & 1.74 & $0.38 * *$ \\
\hline Changing personal behaviour to align it with religious or spiritual values and beliefs & 350 & 4.32 & 1.47 & $0.42 * *$ \\
\hline Actively reflecting on life events in terms of religious beliefs & 351 & 4.19 & 1.46 & $0.37 * *$ \\
\hline Talking about religion or religious beliefs to others & 355 & 4.11 & 1.4 & $0.38 * *$ \\
\hline Service to others & 351 & 4.02 & 1.51 & $0.43 * *$ \\
\hline Taking part in religious rituals & 349 & 3.92 & 1.81 & $0.38 * *$ \\
\hline Reading religious or spiritual material & 350 & 3.73 & 1.43 & $0.33 * *$ \\
\hline Using social media to practice or share religion & 350 & 3.59 & 1.77 & $0.32 * *$ \\
\hline Providing religious or spiritual teaching, guidance or counselling to others & 316 & 3.02 & 1.66 & $0.37 * *$ \\
\hline Meditation & 348 & 2.74 & 1.75 & $0.26 * *$ \\
\hline Fasting & 355 & 2.22 & 1.63 & $0.22 * *$ \\
\hline
\end{tabular}

$S D$, standard deviation; $M$, mean; SWB, spiritual well-being.

Religious practices were measured on a 1 to 6 -point scale with higher scores indicating higher frequencies of practice.

$* *, p<.001$

spiritual books or texts $(t=2.22, d f=140.27, p=0.028$, twotailed, equality of variances not assumed; mean difference $=0.41,95 \%$ CI: -0.78 to -0.04$)$ whereas females more often said grace before meals $(t=-3.01, d f=140.23$, $p=0.003$, two-tailed, equality of variances not assumed; mean difference $=0.65,95 \% \mathrm{CI}:-1.07$ to -0.22$)$ and listened to religious or gospel music more often $(t=-2.02, d f=124.70$, $p=0.046$, two-tailed, equality of variances not assumed; mean difference $=0.41,95 \% \mathrm{CI}:-0.81$ to -0.01$)$. Furthermore, two significant racial differences emerged in that black students were found to be more likely to listen to religious services on television or radio $(t=3.32, d f=19.17, p=0.04$, two-tailed, equality of variances not assumed; mean difference $=1.72,95 \%$ CI: 0.64 to 2.81 ) and to use social media such as Facebook to practice or share their spirituality than white students $(t=2.58, d f=339, p=0.01$, two-tailed; mean difference $=1.07,95 \% \mathrm{CI}: 0.26$ to 1.90$)$. The latter represents a fairly large difference (Cohen's $d=0.59$ ).

To investigate the relationship between students' overall spiritual well-being and the religious practices in which they engage, Pearson's product moment correlations were computed between these variables (Table 4). The results revealed that all religious practices were significantly and positively associated with overall spiritual well-being and that these relationships were generally of moderate strength. Engaging in acts of service and actively working to align their personal behaviour with their spiritual values were the factors most strongly associated with students' spiritual well-being, respectively explaining $18.5 \%\left(R^{2}=0.185\right)$ and $17.6 \%\left(R^{2}=0.176\right)$ of the variance in overall spiritual wellbeing when considered individually. Conversely, fasting, meditation and the attendance of religious services exhibited the weakest associations with this variable, respectively accounting for $5 \%\left(R^{2}=0.048\right), 6.8 \%\left(R^{2}=0.068\right)$ and $6.8 \%$ $\left(R^{2}=0.068\right)$ of the variance of overall spiritual well-being scores. Of note is that a stronger association exists between spiritual well-being and listening to religious services on television or radio than between spiritual well-being and inperson attendance of such services.

\section{Discussion Outline of the results}

The aim of this study was to investigate the religious lives of students by examining their religious affiliation, level of religiosity, spiritual well-being, the maturity of religious attitudes as well as the nature of their religious practices in which they engage and the relationships between such practices and students' spiritual well-being. Additionally, gender, religious and racial differences in these dimensions were also investigated. Taken together, the findings paint a picture of the student group in which $98.9 \%$ consider themselves to be religious to one degree or another, with most being moderately to very religious. The overwhelming majority of participants were Christian. However, the findings also show that a small but significant number of students actively align themselves with traditional African religious belief systems. As such, these indigenous belief systems still appear to be relevant to a small but significant subgroup of the student population. Several studies confirm that traditional religious belief systems continue to exist and have relevance amongst African communities (e.g. Peltzer et al. 2008; Van der Merwe et al. 2010). However, what remains unclear from the present study is what these beliefs entail, whether they are viewed and practised as an independent religious orientation and whether such traditional beliefs might be syncretised with elements of Christianity. The findings reported by Van der Merwe et al. (2010) who studied a similar student group suggest that the latter might be the case as they found that most religious black students' beliefs involve elements of traditional African cosmological assumptions which have been altered to varying degrees by a Christian cosmology. However, the fact that this student group differed in several statistically significant ways from Christian students suggests that real and quantifiable characteristics distinguish these groups, which represent fruitful avenues for future research.

Furthermore, students' attitudes towards their religious beliefs was found to be highly fundamentalist and, as such, are characterised by fairly high levels of conservatism, dogmatism and inter-religious intolerance. Black and 
Christian students were found to be significantly more fundamentalist in their beliefs than white students and those espousing traditional African religious beliefs. The notion of fundamentalism in the context of African traditional religion has been investigated by Sakuba (2008:388) who echoes these findings when he concludes that '... although there is no fullblown "African fundamentalism", certain fundamentalist tendencies can be detected among adherents of African traditional religion'. However, religious fundamentalism was found to be positively associated with all aspects of spiritual well-being (with the exception of environmental spiritual well-being). Whilst several international studies point to negative outcomes associated with fundamentalist and conservative religious orientations, including hopelessness (Cheung \& Kwok 1996), intolerance (Streib et al. 2009), shame (Keller et al. 2015), prejudice and hostility towards minority groups (Altemeyer \& Hunsberger 1992), a positive association between fundamentalism and elevated well-being has also been reported by Pienaar et al. (2006). One of the reasons for this appears to be that fundamentalism enhances life meaning by providing a singular, uncontested and coherent worldview that provides clear-cut answers to life's uncertainties. The heightened sense of life meaning derived from this in turn leads to higher levels of subjective well-being amongst such individuals (Nell 2014; Pienaar et al. 2006).

Overall, students were found to experience high levels of spiritual well-being, especially in terms of transcendental and personal spiritual well-being. Furthermore, all facets of spiritual well-being were positively correlated with religiosity, suggesting that, the more religious students are, the more likely they are to experience higher levels of spiritual wellbeing. Christian students, especially, were found to have levels of transcendent spiritual well-being that exceeded those of students allying themselves with traditional African belief systems. Environmental well-being received the lowest scores (with males obtaining higher scores on this scale than females), which implies a disconnection between (especially female) students' sense of spirituality and their experience of, and connectedness to, nature. The reason for the lower environmental scores are not clear from the data though it might be speculated that factors such as poverty, lack of access to areas of natural beauty, and urbanised lifestyles could be contributing factors. However, these possibilities remain to be investigated in future studies. With scores on communal spiritual well-being also being somewhat lower than the personal and transcendent scales, significant scope exists for interventions aimed at enhancing these specific facets of students' spiritual well-being. Youth and student ministries could play an important role in supporting such well-being by emphasising the communal and environmental aspects of students' religiosity. This could for example be achieved by means of conducting student camps or retreats in nature settings and by promoting communal religious activities.

The most significant and frequent religious activities in which the students engaged revolve around prayer (both generally and before meals) and attending religious services, either in person or, to a slightly lesser degree, listening to a service via a media channel such as radio or television. A relatively large number of students also spent time actively seeking to align their behaviour with their religious beliefs and engaging in acts of religiously motivated service. Fasting and meditation were the practices in which students engaged least frequently, suggesting that such activities are not very important to the student group. In terms of gender differences, it was found that more female than male students listened to gospel music and said grace before meals whereas males were more likely to attend religious services than females. Compared to white students, black participants reported higher frequencies of using social media such as Facebook to share or practice their spirituality and were more prone to listen to religious services or programs on television or radio. Whilst the reasons for these differences were not assessed in the present study, it could be speculated that restrictive financial circumstances and travel costs might make it more challenging for some black students to attend church in person, making virtual participation in such activities via media channels such as television, radio and Facebook a more viable alternative.

Finally, the results revealed that all spiritual practices that were assessed were positively correlated with higher levels of overall spiritual well-being. This association was especially strong in the case of religious practices such as engaging in acts of service and working to align personal behaviour with religious values, but they were less strong in the case of fasting and meditation. The association between religiously motivated service and well-being has been noted repeatedly in previous studies (Pargament et al. 1998). Burnell et al. (2009:1) state that ' $[u]$ rgent research regarding the contribution of congregations to the spiritual well-being of adolescents ... is called for'. Whilst the sample used in this study consisted of students only and though causality cannot be inferred from a cross-sectional study, the results of the present study suggest that religious congregations do play a significant role in the spiritual well-being of students. Furthermore, the fact that virtual attendance of religious services was found to be associated with higher levels of spiritual well-being than in-person attendance of religious services suggests that such channels play an important role in the religious lives and spiritual well-being of significant numbers of students. This implies that the effectiveness of youth and student ministries in promoting spiritual wellbeing amongst students could potentially be enhanced by specifically targeting these channels.

\section{Practical implications of the findings}

The findings made in this study could be of practical use to those concerned with student well-being in general and, specifically, to those working with students in religious contexts as is the case with student and youth ministries. By understanding not just the extent but also the specific nature of the religious lives of students and the ways in which these aspects differ between gender, religious and racial groups, 
religiously based initiatives and interventions aimed at such a population are likely to address the religious and spiritual needs of students more effectively. Several specific guidelines can be extrapolated from the findings: The fact that virtually all students are religious and that all religious practices were found to be positively correlated with spiritual well-being, suggests that efforts aimed at supporting and enhancing the religious lives of students are warranted and highly relevant. Religion constitutes an important avenue through which the spiritual and general psychological well-being of university students can be enhanced (Burnell et al. 2009; Patel et al. 2009). This can be done especially by focusing on and encouraging religious activities that involve positive communal elements and/or connection with nature, which would likely enhance communal and environmental spiritual well-being. Encouraging students to engage in religious practices more frequently and actively is likely to further enhance spiritual well-being, especially concerning practices such as performing acts of service to others and working to align personal behaviour with spiritual values and beliefs. Those working with students in religious contexts such as student ministries might also consider the active use of social media such as Facebook and Twitter as the majority of students actively use these media for spiritual purposes and positively associate it with their spiritual well-being. Finally, although the high level of fundamentalist attitudes that characterised the student group were found to be positively associated with spiritual well-being, the conservatism that underlies such attitudes form the basis of the in-group versus outgroup polarisation that finds its extreme expression in actions such as xenophobia; victimisation of those with different sexual orientations; increased willingness to endorse violence, torture and execution; and the stigmatisation of those with diseases such as AIDS (Altemeyer \& Hunsberger 1992:115; Van Breda 2012). As such, focusing on the cultivation of more mature and tolerant religious views should be an important focus of those concerned with enhancing the religious lives of students.

\section{Limitations and recommendations}

The study has several limitations. Firstly, whilst the sample included both genders and at least eight different cultural groups, white, mixed-race and non-Christian participants were under-represented. Because of the relatively small number of participants in these categories, statistically significant between-group differences might have gone undetected. As such, future studies would be required to investigate whether these findings can be generalised to white and non-Christian student populations elsewhere. Furthermore, whilst no compelling theoretical or empirical evidence seem to exist that imply that the religious lives of the black and Christian students in the present study would differ greatly from those of students in other parts of the country, this would also need to be verified by future research. As the study was based on a cross-sectional design, no inferences about causality can be made. For example, while it seems plausible to suggest that higher levels of religiosity cause elevated spiritual well-being, it is possible that the inverse could be true or that the relationship is mediated by a third variable such as meaning in life. Great scope therefore exists for investigating the causal relationships between specific religious practices and students' spiritual well-being by means of experimental research designs. Finally, this article adopted a predominantly psychological and sociological perspective to the study of the religious lives of students. Future studies could therefore meaningfully supplement the findings reported here by approaching the subject from an overtly theological perspective.

\section{Conclusion}

Whilst generalisation from the findings need to be treated with caution, the results of this study, in which a crosssectional survey design was used to explore the religious lives of South African university students, suggest that the majority of South African university students are religious with most being moderately to very much so. Although most are Christians, it was found that traditional African religious beliefs were espoused by a significant minority of students. Participants' attitudes towards their religious beliefs were characterised by high levels of fundamentalism, but these were associated with enhanced rather than reduced levels of spiritual well-being. Overall, students had high levels of overall spiritual well-being but moderate levels of environmental spiritual well-being. Students engaged in a variety of religious practices of which the most frequent were prayer and attendance of religious services, either in person or via some form of media. Fasting and meditation were the least common religious practices. It is hoped that these findings will be of practical use to those such as student ministries who are working with student populations in religious contexts and within universities to better understand and more effectively address the spiritual needs of this group, thereby supporting the spiritual well-being of South African university students.

\section{Acknowledgements}

All aspects of this study (with the exception of data capturing, which was conducted by the statistical department of the North-West University) were conducted by the author.

\section{Competing interests}

The author declares that he has no financial or personal relationships which may have inappropriately influenced him in writing this article.

\section{References}

Allport, G.W., 1950, The individual and his religion: A psychological interpretation, Macmillan, Oxford.

Altemeyer, B. \& Hunsberger, B., 1992, 'Authoritarianism, religious fundamentalism, quest, and prejudice', International Journal for the Psychology of Religion 2(2), 113-133. http://dx.doi.org/10.1207/s15327582ijpr0202_5

Altemeyer, B. \& Hunsberger, B., 2004, 'A revised religious fundamentalism scale: The short and sweet of it', International Journal for the Psychology of Religion 14(1), 47-54. http://dx.doi.org/10.1207/s15327582ijpr1401_4

Baum, S.K., 2009, 'Christian and Muslim anti-semitic beliefs', Journal of Contemporary Religion 24(2), 137-156. http://dx.doi.org/10.1080/13537900902816632 
Bowman, N.A. \& Smedley, C.T., 2013, 'The forgotten minority: Examining religious affiliation and university satisfaction', Higher Education 65, 745-760. http://dx. aftiliation and university satisfaction

Brace, N., Kemp, R. \& Snelgar, R., 2012, SPSS for psychologists, Palgrave Macmillan, Hampshire.

Burnell, B.M., Beukes, R.B.I. \& Esterhuyse, K.G.F., 2009, 'The relationship between spiritual well-being and a sense of meaning in life in late adolescence', Practical Theology in South Africa 24(1), 1-31.

Cheung, C. \& Kwok, S., 1996, 'Conservative orientation as a determinant of hopelessness', Journal of Social Psychology 136(3), 333-351. http://dx.doi.org/10 $.1080 / 00224545.1996 .9714012$

Del Rio, C.M. \& White, L.J., 2012, 'Separating spirituality from religiosity: A holymorphic attitudinal perspective', Psychology of Religion and Spirituality 4 123-142. http://dx.doi.org/10.1037/a0027552

Diener, E., Tay, L. \& Myers, D.G., 2011, 'The religion paradox: If religion makes people happy, why are so many dropping out?', Journal of Personality and Social Psychology 101, 1278-1290. http://dx.doi.org/10.1037/a0024402

Dollinger, S.J. \& Malmquist, D., 2009, 'Reliability and validity of single-item selfreports: With special reference to college students' alcohol use, religiosity, study, and social life', Journal of General Psychology 136, 321-241. http://dx.doi. and Social life', Journal of General

Ellison, C.W., 1983, 'Spiritual well-being: Conceptualisation and measurement', Journal of Psychology and Theology 11(4), 330-340.

Fowler, J.W., 1981, Stages of faith: The psychology of human development and the quest for meaning, Harper, New York.

Gomez, R. \& Fisher, J.W., 2003, 'Domains of spiritual well-being and development and validation of the spiritual well-being questionnaire', Personality and Individual Differences 35, 1975-1991. http://dx.doi.org/10.1016/S0191-8869(03)00045-X

Hekman, S., 1993, 'Moral voices, moral selves: About getting it right in moral theory' Human Studies 16, 143-162. http://dx.doi.org/10.1007/BF01318576

James, J., Griffiths, B. \& Pedersen, A., 2011, 'The "making and unmaking” of prejudice against Australian Muslims and gay men and lesbians: The role of religious development and fundamentalism', The International Journal for the Psychology of Religion 21, 212-227. http://dx.doi.org/10.1080/10508619.2011.581579

Keller, K.H., Mollen, D. \& Rosen, L.H., 2015, 'Spiritual maturity as a moderator of the relationship between Christian fundamentalism and shame', Journal of Psychology and Theology 43(1), 34-46.

Lippman, L.H. \& Keith, J.D., 2006, 'The demographics of spirituality among youth: International perspectives' in E.C. Roehlkepartain (ed.), The handbook of spiritual development in childhood and adolescence, pp. 110-142, Sage, Thousand Oaks. http://dx.doi.org/10.4135/9781412976657.n8

Moodley, T., Esterhuyse, K.G.F. \& Beukes, R.B.I., 2012, 'Factor analysis of the spiritual well-being questionnaire using a sample of South African adolescents', Religion \& Theology 19, 122-151. http://dx.doi.org/10.1163/15743012-12341239
Muthén, L.K. \& Muthén, B.O., 2012, Mplus user's guide, 6th edn., Muthén \& Muthén, Los Angeles.

Nell, H.W., 2014, 'Exploring the relationship between religious fundamentalism, life satisfaction, and meaning in life', Journal of Psychology in Africa 24(2), 159-166.

Pargament, K.I., Smith, B.W., Koenig, H.G. \& Perez, L.M., 1998, 'Patterns of positive and negative religious coping with major life stressors', Journal for the Scientific Study of Religion 37, 710-724. http://dx.doi.org/10.2307/1388152

Patel, C.J., Ramgoon, S. \& Paruk, Z., 2009, 'Exploring religion, race and gender as factors in the life satisfaction and religiosity of young South African adults', South African Journal of Psychology 39, 266-274.

Peltzer, K., Malaka, D.W. \& Phaswana, N., 2002, 'Sociodemographic factors, religiosity, academic performance, and substance abuse among first-year university students in South Africa', Psychological Reports 91, 105-113. http://dx.doi.org/10.2466/ PR0.91.5.105-113

Peltzer, K., Preez, N.F., Ramlagan, S. \& Fomundam, H., 2008, 'Use of traditional complementary and alternative medicine for HIV patients in KwaZulu-Natal, South Africa', BioMed Central Public Health 8(1), 1-14. http://dx.doi.org/10.1186/1471 2458-8-255

Pienaar, J.M., Beukes, R.B.I. \& Esterhuyse, K.G.F., 2006, 'The relationship between conservatism and psychological well-being in adolescents', South African Journal of Psychology 36(2), 391-406. http://dx.doi.org/10.1177/008124630603600211

Sakuba, X., 2008, 'Fundamentalism in African traditional religion: A reflection on some points for consideration', Scriptura 99, 388-340. http://dx.doi.org/10.7833/99-0678

Sarantakos, S., 2013, Social research, Palgrave Macmillan, London.

Statistics South Africa, 2013, General household survey 2013, viewed 23 November 2015, from http://www.statssa.gov.za/publications/P0318/P03182013.pdf

Streib, H., Wood, R.W. \& Klein, C., 2009, 'The religious schema scale: Construction and initial validation of a quantitative measure for religious styles', The International Journal for the Psychology of Religion 20(3), 151-168. http://dx.doi.org/10.1080/ 10508619.2010.481223

Utsey, S.O., Lee, A., Bolden, M.A. \& Lanier, Y., 2005, 'A confirmatory test of the factor validity of sources on the spiritual well-being scale in a community sample of African Americans', Journal of Psychology and Theology 33(4), 251-257.

Van Breda, A.D., 2012, 'Stigma as "othering" among Christian theology students in South Africa', Journal of Social Aspects of HIV/AIDS 9(4), 181-191. http://dx.doi.or $\mathrm{g} / 10.1080 / 17290376.2012 .745272$

Van der Merwe, E.K., Van Eeden, C. \& Van Deventer, H.J.M., 2010, 'A psychological perspective on god-belief as a source of well-being and meaning', HTS Theological Studies 66(1), 1-10.

Wang, J. \& Wang, X., 2012, Structural equation modeling: Applications using Mplus, Wiley, West Sussex. http://dx.doi.org/10.1002/9781118356258

Wilber, K., 2007, Integral spirituality, Integral Books, London. 